\title{
Synthesis, Characterization and DFT Calculations of 4-((2-Hydroxyethyl)imino)naphthalen-1(4H)-One and its $\mathrm{Cu}(\mathrm{II})$ Complex
}

\author{
G. Gorgulu ${ }^{a, *}$ And B. DedE ${ }^{b}$ \\ ${ }^{a}$ Faculty of Education, Mehmet Akif Ersoy University, Burdur, Turkey \\ ${ }^{b}$ Faculty of Science and Arts, Süleyman Demirel University, Isparta, Turkey
}

\begin{abstract}
We have reported herein the synthesis of a novel quinone derivative ligand containing the Schiff base and its $\mathrm{Cu}$ (II) complex starting from 1,4-naphthoquinone. Synthesized compounds were characterized using the Fourier transform infrared, UV-Vis, elemental analysis, inductively coupled plasma optical emission spectrometry, molar conductivity, and magnetic susceptibility measurements. The free ligand was also characterized by ${ }^{1} \mathrm{H}-$ and ${ }^{13} \mathrm{C}-$ NMR spectra. Elemental analyses, stoichiometric and spectroscopic data indicated that the metal:ligand ratio is 1:2 and octahedral structure is proposed for the metal complex of the Schiff base ligand. Computational quantum calculations were also performed using DFT/B3LYP level of theory with 6-311 $++\mathrm{G}(\mathrm{d}$,p) basis set for the synthesized ligand. It was found that the experimental and theoretical spectroscopic data were consistent.
\end{abstract}

DOI: 10.12693/APhysPolA.133.239

PACS/topics: Schiff base, quinone, metal complex, spectroscopy, copper(II), DFT

\section{Introduction}

Molecules with the quinoid structure constitute one of the most interesting classes of compounds in organic chemistry [1]. The chemistry of quinones is largely dependent on the substituents being either on the quinonic or on adjacent rings. This is reflected in their chemical reactivity, especially in heterocyclic quinines [2]. A Schiff base is a nitrogen analogue of an aldehyde or ketone in which the $\mathrm{C}=\mathrm{O}$ group is replaced by $\mathrm{C}=\mathrm{N}-\mathrm{R}$ group. The Schiff bases are usually formed by condensation reaction of an aldehyde or ketone with a primary amine under specific conditions. They are used as pigments and dyes, catalysts, intermediates in organic synthesis, and as polymer stabilisers [3]. The Schiff bases have also been shown to exhibit a broad range of biological activities, including antifungal, antibacterial, antimalarial, antiproliferative, anti-inflammatory, antiviral, and antipyretic properties [3, 4]. Multidentate Schiff base complexes are well known to form stable complexes, where the coordination takes place through the various donor sets [5-7].

Synthesis and characterization of novel ligand including imine group and its $\mathrm{Cu}(\mathrm{II})$ complex are reported in this study. Additionally, quantum chemical calculations were performed for the synthesized ligand. DFT/B3LYP level of theory with 6-311++G(d,p) basis set was used to optimize the geometry of molecule. The vibrational frequencies, isotropic chemical shifts $\left({ }^{1} \mathrm{H}\right.$ - and ${ }^{13} \mathrm{C}-\mathrm{NMR}$ ), electronic transition absorption wavelengths, highest occupied-lowest unoccupied molecular orbitals

\footnotetext{
* corresponding author; e-mail: guvencgorgulu@mehmetakif . edu.tr
}

(HOMO-LUMO) energy gap and molecular electrostatic potential (MEP) of the synthesized ligand were also calculated.

\section{Experimental}

All starting materials and solvents used for synthesis were of commercially available reagent grade and were used without further purification.

\subsection{Physical measurements}

${ }^{1} \mathrm{H}$ - and ${ }^{13} \mathrm{C}-\mathrm{NMR}$ spectra of the Schiff base ligand were recorded on a JEOL NMR-400 MHz spectrometer in $\mathrm{CDCl}_{3}$ with using TMS internal standard. Elemental analyses $(\mathrm{C}, \mathrm{H}, \mathrm{N})$ were determined by a LECO 932 CHNS analyzer. Metal content of complex was detected by using Perkin Elmer Optima 5300 DV ICP-OES spectrometer. IR spectra were measured by prepared $\mathrm{KBr}$ pellet at Schimadzu IR Prestige-21 FT-IR spectrophotometer within the range $4000-400 \mathrm{~cm}^{-1}$. Magnetic susceptibility measurements were done on a Sherwood Scientific Magnetic Susceptibility Balance (model MX1) at room temperature. The conductance measurements were carried out using an Optic Ivymen System conductivity meter. Melting point determinations were performed with a digital melting point instrument from Electrothermal model IA 9100. Spectrophotometric measurements were performed with PG $80+$ UV-Vis spectrophotometer.

\subsection{Synthesis of the Schiff base ligand [HL]}

An absolute ethanol solution $(15 \mathrm{ml})$ of ethanolamine $(10 \mathrm{mmol})$ was added to absolute ethanol solution $(15 \mathrm{ml})$ of 1,4-naphthoquinone (10 mmol). The contents were refluxed for $3 \mathrm{~h}$ and left overnight at $25^{\circ} \mathrm{C}$. The compound 
which precipitated was filtered off and washed several times with cold ethanol and dried on $\mathrm{P}_{2} \mathrm{O}_{5}$.

Brown compound; yield: $76 \%$; m.p.: $160^{\circ} \mathrm{C}$. Anal. calc. for $\mathrm{C}_{12} \mathrm{H}_{11} \mathrm{NO}_{2}$ : C, 71.63; H, 5.51; N, 6.96; found: $\mathrm{C}, 71.52 ; \mathrm{H}, 5.63 ; \mathrm{N}, 6.81 \% ;{ }^{1} \mathrm{H}-\mathrm{NMR}\left(\mathrm{CDCl}_{3}, \mathrm{ppm}\right)$ : theor. calc. $6.66(1 \mathrm{H}, \mathrm{O}-\mathrm{H}), 7.71-8.56(4 \mathrm{H}, \mathrm{Ar}-\mathrm{H}), 7.18$ $(2 \mathrm{H},-\mathrm{C} 8 \mathrm{H}-$ and $-\mathrm{C} 9 \mathrm{H}-), 3.90\left(2 \mathrm{H},-\mathrm{C}^{3} 3 \mathrm{H}_{2}-\right) ; 3.14(2 \mathrm{H}$, $\left.{ }_{-} \mathrm{C} 14 \mathrm{H}_{2}-\right)$; found: 6.19 (s, $\left.1 \mathrm{H}, \mathrm{O}-\mathrm{H}\right), 7.59-8.25(\mathrm{~m}, 4 \mathrm{H}$, $\mathrm{Ar}-\mathrm{H}), 7.21$ (d, 2H, $-\mathrm{C} 8 \mathrm{H}-$ and $-\mathrm{C} 9 \mathrm{H}-), 3.89(\mathrm{t}, 2 \mathrm{H}$, $\left.{ }^{-} \mathrm{C}_{13} \mathrm{H}_{2}-\right) ; 3.35$ (t, $\left.2 \mathrm{H},-\mathrm{C}_{14 \mathrm{H}_{2}-}\right)$; ${ }^{13} \mathrm{C}-\mathrm{NMR}\left(\mathrm{CDCl}_{3}\right.$, ppm): theor. calc. 197.86 (carbonyl), 166.68 (imine), 129.20-139.05 (aromatic), 140.17 (C8 and C9), 67.23 (C13), 58.32 (C14); found: 195.24 (carbonyl), 164.47 (imine), 127.18-13642 (aromatic), 138.27 (C8 and C9) 65.89 (C13), 60.45 (C14); FT-IR $\left(\mathrm{KBr}, \mathrm{cm}^{-1}\right)$ : theor. calc. $3274 \mathrm{~b}(\mathrm{O}-\mathrm{H}), 1659 \mathrm{~s}(\mathrm{C}=\mathrm{O}), 1622 \mathrm{~m}(\mathrm{C}=\mathrm{N}), 1215$ $\mathrm{s}(\mathrm{C}-\mathrm{O})$; found: $3256 \mathrm{~b}(\mathrm{O}-\mathrm{H}), 1671 \mathrm{~s}(\mathrm{C}=\mathrm{O}), 1610 \mathrm{~m}$ $(\mathrm{C}=\mathrm{N}), 1236$ s $(\mathrm{C}-\mathrm{O})$ (b, broad; s, strong; m, medium; $\mathrm{w}$, weak); UV-Vis (ethanol solution, nm): theor. calc. 262, 314, 377; found: 271, 332, 386 .

\subsection{Synthesis of $\mathrm{Cu}(\mathrm{II})$ Schiff base complex $\left[\mathrm{CuL}_{2}\left(\mathrm{H}_{2} \mathrm{O}\right)_{2}\right]$}

A solution of $1 \mathrm{mmol} \mathrm{Cu}$ (II) acetate in ethanol $(10 \mathrm{ml})$ was added to the $2 \mathrm{mmol}$ ligand (HL) dissolved in $10 \mathrm{ml}$ ethanol. The resulting mixture was refluxed for $2 \mathrm{~h}$. The complex was precipitated after cooling. The solid complex was filtered, washed with ethanol and diethyl ether and finally dried over $\mathrm{P}_{2} \mathrm{O}_{5}$.

Black compound; yield: $64 \%$; m.p.: $187^{\circ} \mathrm{C}$. Anal. calc. for $\mathrm{C}_{24} \mathrm{H}_{24} \mathrm{CuN}_{2} \mathrm{O}_{6}$ : C, 57.65; H, 4.84; N, 5.60; Cu, 12.71; found: C, 57.43; H, 5.57; N, 6.97; Cu, 12.58\%; FT-IR $\left(\mathrm{KBr}, \mathrm{cm}^{-1}\right): 3534 \mathrm{~b}\left(\mathrm{O}-\mathrm{H}_{\text {water }}\right), 1668 \mathrm{~s}(\mathrm{C}=\mathrm{O}), 1591 \mathrm{~m}$ $(\mathrm{C}=\mathrm{N}), 1267 \mathrm{~s}(\mathrm{C}-\mathrm{O}), 537 \mathrm{w}(\mathrm{Cu}-\mathrm{O}), 425 \mathrm{w}(\mathrm{Cu}-\mathrm{N})(\mathrm{b}$, broad; s, strong; m, medium; w, weak); UV-Vis (ethanol solution, nm): 274, 306, 402, 476, 588; $\Lambda_{M}$ (DMF solution, $\left.\Omega^{-1} \mathrm{~cm}^{2} \mathrm{~mol}^{-1}\right): 14.50 ; \mu_{e f f}=1.78$ B.M.

\subsection{Computational methods}

All calculations were carried out with Gaussian 09 program on a personal computer [8]. GaussView 5.0.9 software package were used for molecular visualizations [9]. The molecular geometry of the ligand was fully optimized in gas phase using density functional theory (DFT) based B3LYP method along with $6-311++\mathrm{G}(\mathrm{d}, \mathrm{p})$ basis set. The same basis set was employed for computing vibrational frequencies. UV-Vis spectra and HOMO and LUMO energies were determined by time dependent DFT (TD-DFT) method at the B3LYP level. ${ }^{1} \mathrm{H}-$ and ${ }^{13} \mathrm{C}-$ NMR shielding constants were calculated by applying gauge-invariant atomic orbital (GIAO) method.

\section{Results and discussion}

The Schiff base ligand 4- $((2-$ hydroxyethyl)imino)naphthalen-1 $(4 H)$-one (HL) was prepared by a condensation reaction between 1,4naphthoquinone and ethanolamine. The synthesis reaction of novel ligand is illustrated in Fig. 1.

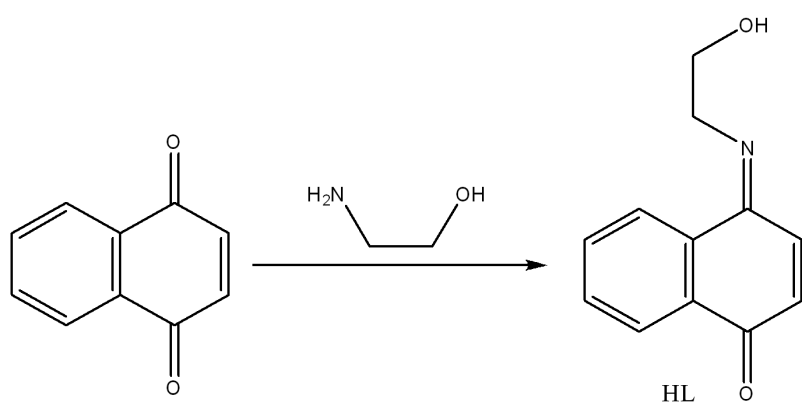

Fig. 1. Preparation of the ligand HL.

The mononuclear $\mathrm{Cu}(\mathrm{II})$ complex was synthesized by reaction of the ligand mixture in ethanol with copper(II) acetate. The synthesized $\mathrm{Cu}(\mathrm{II})$ complex obtained in powder form is stable at room temperature. The melting points, yields, colours, elemental analyses, magnetic moment, and molar conductivity value of compounds are given in experimental section. According to the elemental analyses and inductively coupled plasma optical emission spectrometry (ICP-OES), synthesized $\mathrm{Cu}(\mathrm{II})$ complex of the Schiff base ligand have a 1:2 metal:ligand ratio.

\section{1. ${ }^{1} H$ - and ${ }^{13} C$-NMR spectra}

The ${ }^{1} \mathrm{H}$ - and ${ }^{13} \mathrm{C}-\mathrm{NMR}$ spectra of the ligand provided well-resolved signals. The chemical shifts, expressed in ppm downfield form of tetramethylsilane (TMS), are given in the experimental section. Theoretical calculations were carried out to confirm the accuracy of the obtained experimental data. The molecular geometry of the ligand HL was optimized prior to calculating the theoretical chemical shifts. B3LYP functional with 6$311++\mathrm{G}(\mathrm{d}, \mathrm{p})$ basis set was used for ${ }^{1} \mathrm{H}$ - and ${ }^{13} \mathrm{C}-\mathrm{NMR}$ chemical shift calculations. The GIAO [10, 11] method, used for defining isotropic nuclear magnetic shielding tensors, is one of the most common approaches. The isotropic shielding values used to calculate the isotropic chemical shifts with respect to TMS are also given in the experimental section. As can be seen from Fig. 2 and Fig. 3, experimental and theoretically calculated NMR spectra are quite compatible.

Deuterium exchangeable proton of the $-\mathrm{OH}$ group showed a chemical shift at $6.19 \mathrm{ppm}$ as a singlet peak in ${ }^{1} \mathrm{H}-\mathrm{NMR}$ spectrum of the ligand [12]. Its corresponding calculated chemical shift appeared at $6.66 \mathrm{ppm}$. All the multiplet signals in the $7.59-8.25 \mathrm{ppm}$ range were assigned to the protons of the aromatic rings. Chemical shifts at 3.89 and $3.35 \mathrm{ppm}$ can be attributed to the methylene group protons which are close to the nitrogen and oxygen atom, respectively. These values were calculated as 3.90 and 3.14 ppm.

${ }^{13} \mathrm{C}-\mathrm{NMR}$ spectrum of ligand HL displayed a resonance at $164.47 \mathrm{ppm}$ for azomethine carbon atom which confirms the structure of the ligand [13]. Corresponding signal was observed at $166.68 \mathrm{ppm}$ in theoretical spectrum. The chemical shift values of the carbonyl carbon atom 
of HL appeared at $195.24 \mathrm{ppm}$. All signals in 127.18 $136.42 \mathrm{ppm}$ range are assigned to carbon atoms of the aromatic rings. Signals observed at 65.89 (C13) and 60.45 (C14) ppm are attributable to carbon atom of the methylene groups of the ligand which are close to the nitrogen and oxygen atom, respectively. DFT calculated values of methylene carbons observed at 67.23 and $58.32 \mathrm{ppm}$ are in good agreement with the experimental data.

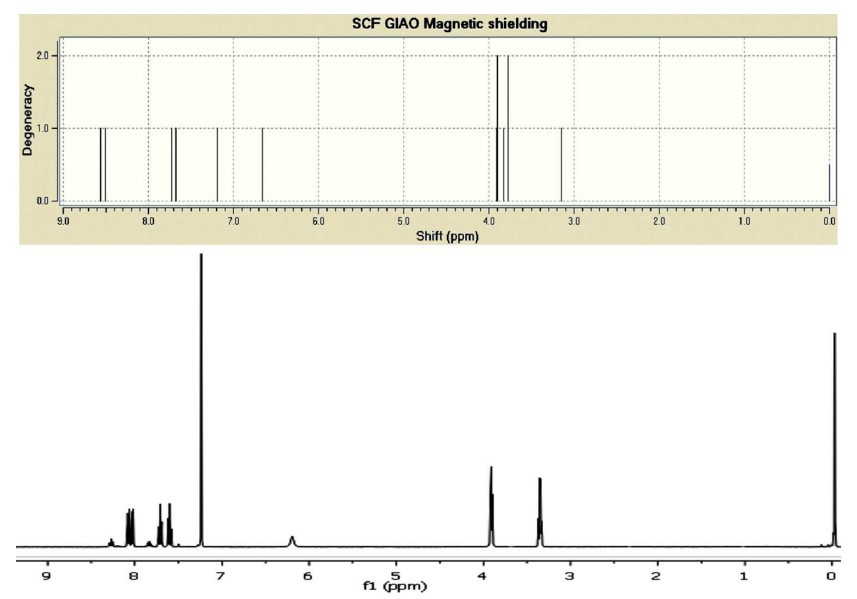

Fig. 2. Calculated (upper) and experimental (lower) ${ }^{1} \mathrm{H}-\mathrm{NMR}$ spectra of the ligand (HL).

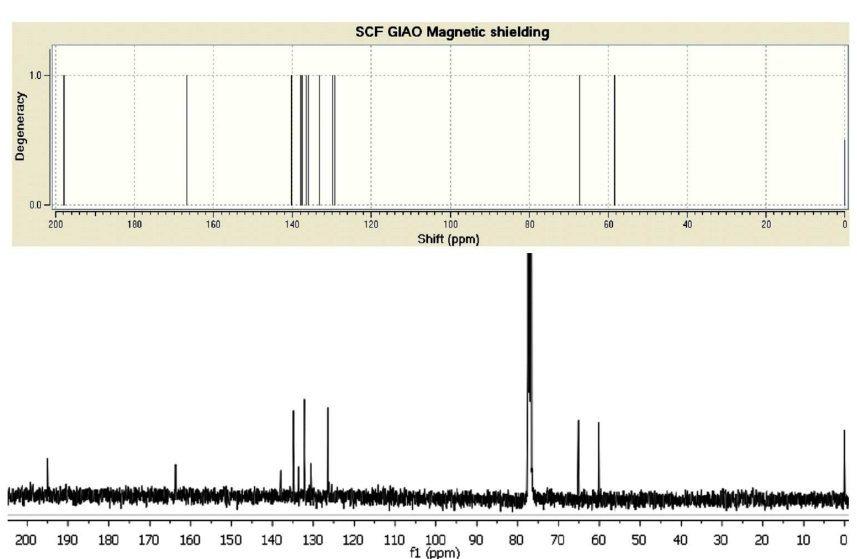

Fig. 3. Calculated (upper) and experimental (lower) ${ }^{13} \mathrm{C}-\mathrm{NMR}$ spectra of the ligand (HL).

\subsection{FT-IR spectra}

The IR spectra of the ligand HL and its mononuclear $\mathrm{Cu}$ (II) complex were obtained in $4000-400 \mathrm{~cm}^{-1}$ range. In addition, IR spectra of the ligand were also calculated at the B3LYP $/ 6-311++\mathrm{G}(\mathrm{d}, \mathrm{p})$ level and significant vibrational wave numbers were selected. However, the unscaled vibrational frequencies frequently give results higher than observed ones, due to the described systematic errors exclusion of anharmonicity defective treatment of electron correlation and truncation of the basis set [14]. For these reasons, the calculated vibrational wave numbers were scaled as 0.983 for frequencies lower than $1700 \mathrm{~cm}^{-1}$ and 0.958 for frequencies higher than $1700 \mathrm{~cm}^{-1}$ for B3LYP $/ 6-311++\mathrm{G}(\mathrm{d}, \mathrm{p})$ basis set $[15,16]$. Significant experimental and calculated IR spectral bands are given in the experimental section.

The IR spectrum of the ligand show a broad band at $3256 \mathrm{~cm}^{1}$, which can be attributed to $\mathrm{OH}$ group of alcohol moiety [17]. The corresponding calculated value of $3274 \mathrm{~cm}^{-1}$ is quite consistent with the experimental value. This band disappeared in the experimental spectrum of $\mathrm{Cu}(\mathrm{II})$ complex indicating that the $\mathrm{OH}$ proton was separated with complex formation and bonded to the $\mathrm{Cu}$ (II) ion. Stretching vibration for $\mathrm{C}-\mathrm{O}$ bond in the spectrum of the ligand is recorded at $1236 \mathrm{~cm}^{-1}$. The same vibration appears in the theoretical calculations at $1215 \mathrm{~cm}^{-1}$. The shifting of $\nu(\mathrm{C}=\mathrm{N})$ stretching vibration to $1267 \mathrm{~cm}^{-1}$ confirms the involvement of oxygen atom in coordination with $\mathrm{Cu}(\mathrm{II})$ ion. This coordination mode is further supported by the appearance of a new band at $537 \mathrm{~cm}^{-1}$ assigned to $\nu(\mathrm{M}-\mathrm{O})$.

In the free ligand $\nu(\mathrm{C}=\mathrm{N})$ is observed at $1610 \mathrm{~cm}^{-1}$ which was theoretically calculated as $1622 \mathrm{~cm}^{-1}$. The shift of this band towards lower frequencies by $19 \mathrm{~cm}^{1}$ in the spectrum of the complex suggests the participation of the imine nitrogen atom in complex formation. Coordination of the imine nitrogen atom in the complex is also supported by the appearance of a new band assigned to $\nu(\mathrm{M}-\mathrm{N})$ at $425 \mathrm{~cm}^{-1}$.

\section{3. $U V$-Vis measurements}

The electronic spectra of the ligand and its $\mathrm{Cu}(\mathrm{II})$ complex were recorded in ethanol as $10^{-3} \mathrm{M}$ at room temperature. UV-Vis spectrum of the synthesized ligand was also theoretically calculated using TD-DFT method. Calculated electronic transition absorption wavelengths are given with experimental data in the experimental section. The band at $271 \mathrm{~nm}$ in electronic spectra of ligand, was assigned to $\pi \rightarrow \pi^{*}$ transitions of aromatic ring which seemed to not have been affected prominently by the complex formation. On the other hand, electronic transition at $332 \mathrm{~nm}$ originated from $\pi \rightarrow \pi^{*}$ transition of the imine group was obtained as $312 \mathrm{~nm}$ from theoretical calculations. $\pi \rightarrow \pi^{*}$ transition was shifted as $26 \mathrm{~nm}$ to higher energy levels after the formation of the complex which can be attributed to the coordination of nitrogen atom of the imine group with $\mathrm{Cu}(\mathrm{II})$ ion. Electronic spectra of the ligand showed an intense band at $386 \mathrm{~nm}$ which was assigned to $n \rightarrow \pi^{*}$ transition of nonbonding electrons present on the nitrogen atom of the imine group. Theoretically calculated band for $n \rightarrow \pi^{*}$ transition of imine group was nearly same in ethanol ( $c a$. $377 \mathrm{~nm}$ ). The band at $386 \mathrm{~nm}$ was shifted by the complex formation as $16 \mathrm{~nm}$ to a longer wavelength which supported nitrogen atom's participation in the coordination. Finally, the electronic spectrum of $\mathrm{Cu}(\mathrm{II})$ complex exhibited two low intensity bands at 476 and $588 \mathrm{~nm}$ which may be assigned to charge transfer and $d \rightarrow d$ transitions, respectively. 


\subsection{Molar conductance}

The molar conductance of the complex was an aid for proposing its molecular structure. Conductivity measurement was performed in $10^{-3} \mathrm{M} N N$ dimethylformamide solution at $20^{\circ} \mathrm{C}$ and given in the experimental section. The molar conductance of the synthesized mononuclear $\mathrm{Cu}(\mathrm{II})$ complex was measured as $12 \Omega^{-1} \mathrm{~cm}^{2} \mathrm{~mol}^{-1}$ which indicated that there were no ionic species in the complex structure and it belongs to non-electrolytes [18].

\subsection{Magnetic studies}

The magnetic susceptibility measurements showed that the synthesized complex $\mathrm{CuL}_{2}\left(\mathrm{H}_{2} \mathrm{O}\right)_{2}$ is paramagnetic at ambient temperature. The magnetic moment value of the complex was 1.78 B.M. at room temperature which was quite close to the value expected. Although it is not possible to make a complete decision on geometry by the data obtained from the magnetic study, synthesized complex fits a spin value of 1.73 B.M. which is consistent with an octahedral geometry.

\subsection{Computational details}

Geometry optimization of the ligand was done using Becke-3-Lee-Yang-Parr (B3LYP) functional with 6$311++\mathrm{G}(\mathrm{d}, \mathrm{p})$ basis sets in gas phase $[19,20]$. The fully optimized and numbered geometry of the ligand is shown in Fig. 4. The calculated bond length for $\mathrm{C} 14-\mathrm{O} 15$ was $1.448 \AA$. C7-N12 and C10-O11 double bond lengths were found to be as 1.298 and $1.254 \AA$, respectively. On the other hand, the calculated values for the C1-C4-C7-N12 and $\mathrm{C} 4-\mathrm{C} 7-\mathrm{N} 12-\mathrm{C} 13$ dihedral angles were found as 1.340 and $178.897^{\circ}$, respectively. These results revealed that the aromatic ring and ethanolamine moiety of the ligand are lying in the same plane.

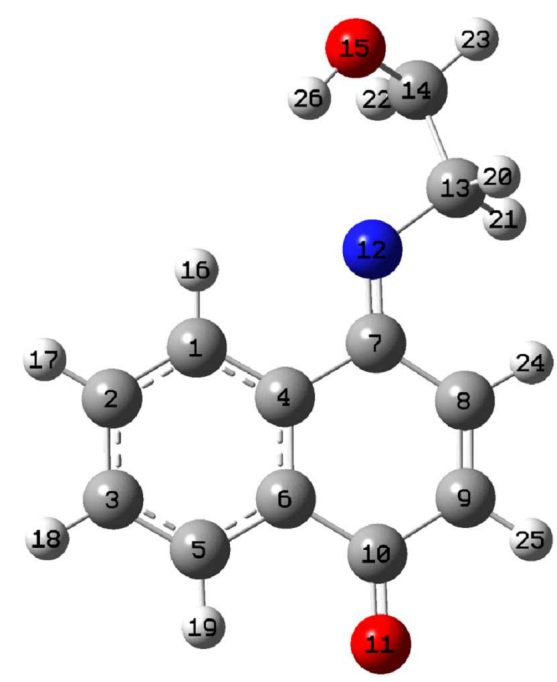

Fig. 4. Optimized geometry and atomic numbering of the ligand (HL).

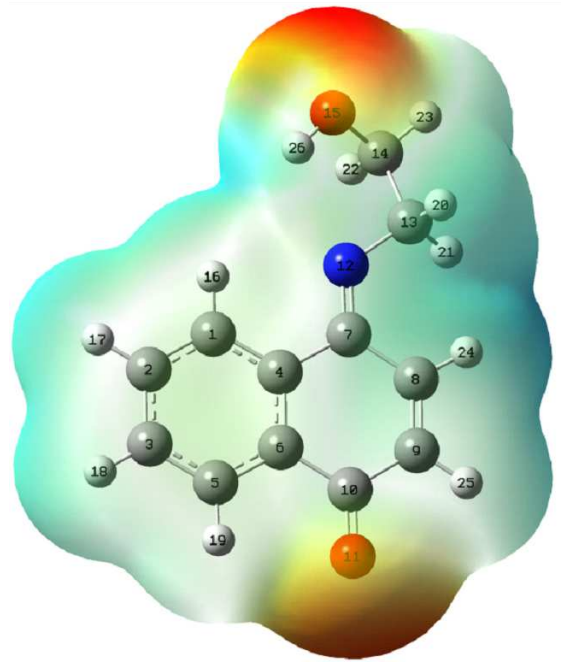

Fig. 5. Molecular electrostatic potential surface of the ligand (HL).

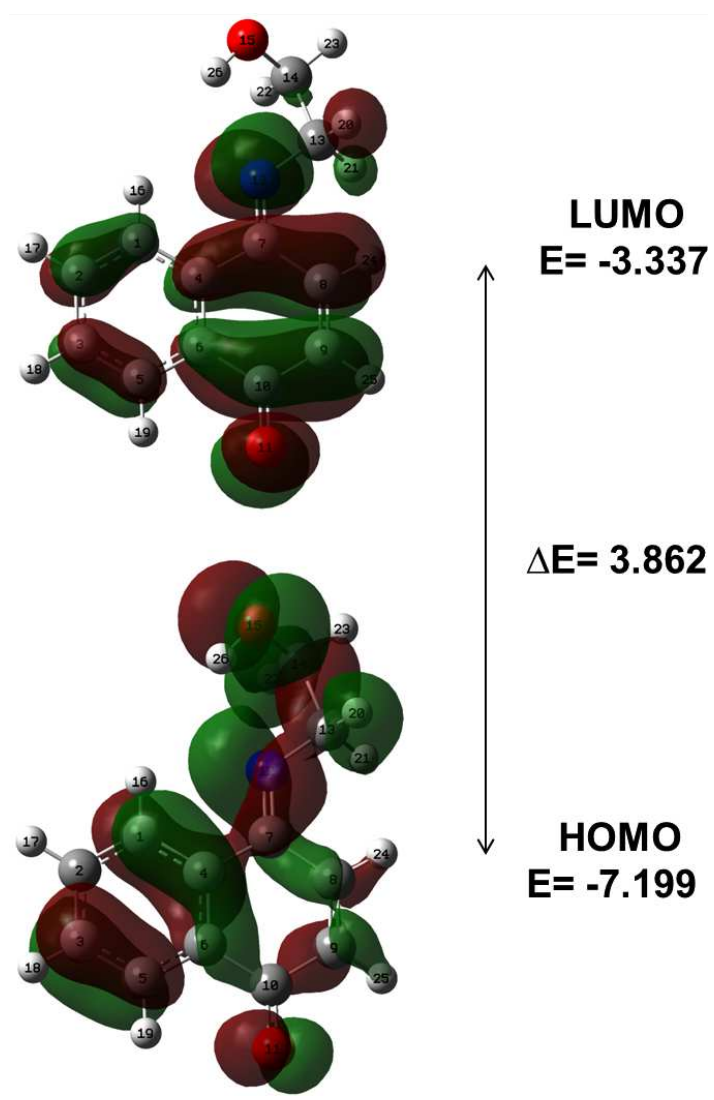

Fig. 6. Frontier molecular orbitals of the ligand (energies are given in $\mathrm{eV}$ ).

The molecular electrostatic potential (MEP) surface of the ligand was calculated using the optimized molecular structure at the B3LYP/6-311++G(d,p) level and its plot is given in Fig. 5. As can be seen from Fig. 5, the negative regions of MEP are mainly localized on O11 and $\mathrm{O} 15$ atoms. Since the O15 atom has an ionizable proton, this oxygen atom and an unpaired electron bearing nitrogen atom of imine group are the possible sites 
for nucleophilic attack. This feature of the ligand is the key reason why the ligand was coordinated via $\mathrm{O} 15$ and $\mathrm{N} 12$ atoms to the $\mathrm{Cu}(\mathrm{II})$ ion.

The HOMO and LUMO of the ligand were computed in the gaseous phase using B3LYP method with $6-311++\mathrm{G}$ $(d, p)$ basis set. The surface plots of HOMO and LUMO are shown in Fig. 6.

Calculated energy value for the HOMO-LUMO gap was $3.862 \mathrm{eV}$. HOMO electrons were localized on most of the atoms except some hydrogen atoms while LUMO were localized on most of the atoms except some hydrogen, oxygen atom of $-\mathrm{OH}$ group, and aliphatic carbon atoms.

\section{Conclusion}

The design and synthesis of a novel Schiff base ligand and its mononuclear $\mathrm{Cu}$ (II) complex were demonstrated in this report. From the elemental analyses, stoichiometric and spectroscopic studies discussed above, the ligand was shown to act as a bidentate which coordinates through the nitrogen atom of the imine group and oxygen atom of the $-\mathrm{OH}$ group. Two ligands coordinated with the $\mathrm{Cu}(\mathrm{II})$ ion and an octahedral geometric complex formed with two moles of coordination water (Fig. 7).

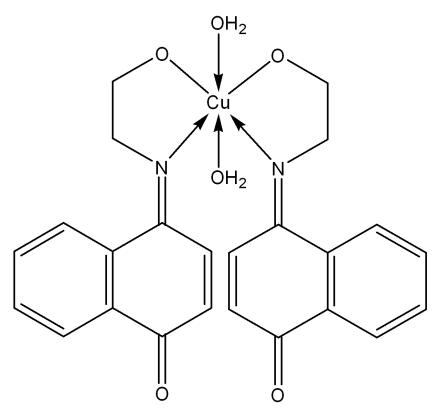

Fig. 7. Structure of the octahedral complex $\left[\mathrm{CuL}_{2}\left(\mathrm{H}_{2} \mathrm{O}\right)_{2}\right]$.

Calculated geometric parameters, vibrational frequencies ${ }^{1} \mathrm{H}$ - and ${ }^{13} \mathrm{C}-\mathrm{NMR}$ spectra and electronic transition absorption wavelengths of the title molecule by using the DFT/B3LYP method with the $6-311++\mathrm{G}(\mathrm{d}, \mathrm{p})$ basis set were in a good agreement with those of the experiments.

\section{References}

[1] S. Spyroudis, Molecules 5, 1291 (2000).

[2] M. Tisler, Heterocyclic Quinones, in: Advances in Heterocyclic Chemistry, Ed. A.R. Katritzky, Academic Press, London 1989, p. 37.
[3] D.N. Dhar, C.L. Taploo, J. Sci. Ind. Res. 41, 501 (1982).

[4] P. Przybylski, A. Huczynski, K. Pyta, B. Brzezinski, F. Bartl, Curr. Org. Chem. 13, 124 (2009).

[5] E.M. Nour, A.A. Taha, I.S. Alnaimi, Inorg. Chim. Acta 141, 139 (1988).

[6] E.M. Nour, A.M. Al-Kority, S.A. Sadeek, S.M. Teleb, Syn. React. Inorg. Met. 23, 39 (1993).

[7] W. Wang, F.L. Zeng, X. Wang, M.Y. Tan, Polyhedron 15, 1699 (1996).

[8] M.J. Frisch, G.W. Trucks, H.B. Schlegel, G.E. Suzerain, M.A. Robb, J.R. Cheeseman Jr. J.A. Montgomery, T. Vreven, K.N. Kudin, J.C. Burant, J.M. Millam, S.S. Iyengar, J. Tomasi, V. Barone, B. Mennucci, M. Cossi, G. Scalmani, N. Rega, G.A. Petersson, H. Nakatsuji, M. Hada, M. Ehara, K. Toyota, R. Fukuda, J. Hasegawa, M. Ishida, T. Nakajima, Y. Honda, O. Kitao, H. Nakai, M. Klene, X. Li, J.E. Knox, H.P. Hratchian, J.B. Cross, V. Bakken, C. Adamo, J. Jaramillo, R. Gomperts, R.E. Stratmann, O. Yazyev, A.J. Austin, R. Cammi, C. Pomelli, J.W. Ochterski, P.Y. Ayala, K. Morokuma, G.A. Voth, P. Salvador, J.J. Dannenberg, V.G. Zakrzewski, S. Dapprich, A.D. Daniels, M.C. Strain, O. Farkas, D.K. Malick, A.D. Rabuck, K. Raghavachari, J.B. Foresman, J.V. Ortiz, Q. Cui, A.G. Baboul, S. Clifford, J. Cioslowski, B. Stefanov, G. Liu, A. Liashenko, P. Piskorz, I. Komaromi, R.L. Martin, D.J. Fox, T. Keith, M.A. Al-Laham, C.Y. Peng, A. Nanayakkara, M. Challacombe, P.M.W. Gill, B. Johnson, W. Chen, M.W. Wong, C. Gonzalez, J.A. Pople, Gaussian 09 (now Gaussian 16), Gaussian Inc., Wallingford (CT) 2016.

[9] GaussView, Revision 5.0.9, R. Dennington, T.A. Keith, J.M. Millam, Semichem Inc., Shawnee Mission, KS, 2009.

[10] R. Ditchfield, J. Chem. Phys. 56, 5688 (1972).

[11] K. Wolinski, J.F. Hinton, P. Pulay, J. Am. Chem. Soc. 112, 8251 (1990).

[12] A. Coşkun, F. Yllmaz, Turk. J. Chem. 32, 305 (2008).

[13] P.E. Aranha, M.P. dos Santos, S. Romera, E.R. Dockal, Polyhedron 26, 1373 (2007).

[14] A. Abbas, H. Gokce, S. Bahceli, M.M. Naseer, J. Mol. Struct. 1075, 352 (2014).

[15] K. Balc1, S. Akyuz, Vibrat. Spectrosc. 48, 215 (2008).

[16] N. Sundaraganesan, S. Ilakiamani, H. Saleem, P.M. Wojciechowski, D. Michalska, Spectrochim. Acta A 61, 2995 (2005).

[17] F. Karipcin, H.İ. Uçan, İ. Karataş, Transit. Met. Chem. 27, 813 (2002).

[18] W.J. Geary, Coord. Chem. Rev. 7, 81 (1971).

[19] A.D. Becke, Phys. Rev. A 38, 3098 (1988).

[20] C. Lee, W. Yang, R.G. Parr, Phys. Rev. B 37, 785 (1988). 